\title{
W(h)ither the Full Season: An Empirical Model for Predicting the Duration of New Television Series' First Season
}

\author{
Starling David Hunter ${ }^{1}$, Yelitza Prada Breen ${ }^{2}$ \\ ${ }^{1}$ School of Business, Carnegie Mellon University, Doha, Qatar \\ ${ }^{2}$ UCLA Extension School Film Program, Los Angeles, CA, USA \\ Email: starling@mit.edu,starling@qatar.cmu.edu
}

How to cite this paper: Hunter, S. D., \& Breen, Y. P. (2017). W(h)ither the Full Season: An Empirical Model for Predicting the Duration of New Television Series' First Season. Advances in Journalism and Communication, 5, 83-97.

https://doi.org/10.4236/ajc.2017.52005

Received: March 30, 2017

Accepted: June 11, 2017

Published: June 15, 2017

Copyright $\odot 2017$ by authors and Scientific Research Publishing Inc. This work is licensed under the Creative Commons Attribution International License (CC BY 4.0).

http://creativecommons.org/licenses/by/4.0/

\begin{abstract}
Television seasons have gotten shorter and shorter over the past few decades. This has been especially true for new dramatic television series where the norm has dropped to thirteen episodes from almost double that figure twenty years ago. Somewhat surprisingly, there is a dearth of empirical research on this question. In this study, we build on recent research in the field of cultural economics to test the effect of three factors on the duration of new television series' first season-the originality of the series' premise, the track record of its creators, and the cognitive complexity of the pilot episode script. As expected, we find that in a sample of 165 new dramatic series debuting in the nine most recently completed seasons, these three factors-both individually and in combination-positively impact both the number of episodes of a new series and the likelihood that new series gets a "full" first season.
\end{abstract}

\section{Keywords}

Content Analysis, Network Text Analysis, Cognitive Complexity, Pilot Episodes, Television, Film and Television, Television Series, Television Programming, Green Lighting, Applied Linguistics

\section{Introduction}

In January of 1968 an article entitled "Viewers Getting Less and Less" appeared in the Los Angeles Times (Humphrey, 1968). The "less" that viewers were receiving was the number of new episodes that comprised a full season of network television. Specifically, the author made note of the fact that between 1958-1963, the standard schedule of 39 new episodes with 13 repeats had been "gradually" decreased by a third to a mere 26 episodes with 20 - 22 repeats and another 4 - 6 
special programs that were "pre-empting the series' (regular) time slot". The rationale for reducing the number of episodes, Humphrey said, was largely economic: as production costs increased, "the networks took the only way out and bought fewer episodes to balance their program budgets."

By any objective account, the trend toward shorter seasons has continued right up to the present day. And just like in the 1960's, commentators and industry insiders are making note of the fact, now in articles with titles like "How U.S. TV Wound Up with Fewer Episodes" (Weinman, 2010), "More Broadcast Series Get 13-Episode Short Orders" (Crupi, 2011), "TV is Moving towards Shorter Seasons" (Hinckley 2013), "The Problem with 22-episode Seasons" (Brew, 2014), "Power of 10: Why Networks are Ordering Shorter Seasons for their Hit Shows" (Lynch, 2015), and "5 Reasons Why Networks are Ordering Shorter Seasons" (Nededog, 2015).

While a comprehensive summary of all suspected causes of the reduction in season length is beyond the scope of this paper, we can say that they fall into three broad and somewhat inter-related categories-micro-economic, i.e. those concerning budgets, expenses, and costs of producing television series, as well as revenues and profits associated with the same; competitive, i.e. those concerning the actions and motivations of competitors and/or providers of substitutes to network television programming; and creative, i.e. issues concerning the needs, demands, preferences, availability, etc. of series creators, writers, and actors, as well as the quality of their work product. As already suggested, foremost in the first category is discussion of the rapidly "escalating production costs" (Crupi, 2011) for television series. In addition, there is the change in the economics of syndication. Until relatively recently, television series needed to reach 100 episodes before they could be profitably run in syndication (Adalian, 2015). But with the advent of streaming and cable sites that emphasize the breadth of their collections rather than depth in selected or "hit" shows, the consideration is no longer as important as it once was.

Foremost in the second category is the sharp decline in ratings of network television shows brought about, in large part, by the expansion of cable and streaming outlets. According to Crupi (2011), this state of affairs has lead broadcasters to undertake a "radical rethink of how they program prime time." Among the most notable strategic responses has been the widespread adoption of cutting the length of initial orders for news series down to 13 episodes with an option to add up to nine more episodes if the series performs well, as well as the option to reduce the order if the show performs particularly poorly (Brew, 2014). Others have noted that in recent years, that initial order has fallen to as few as 10 episodes or less (Lynch, 2015). But economic and competitive forces are rarely divorced from one another. And in Brew's (2014) case, the economic justification for this approach is that networks can cut losers faster and let the winners run, thereby minimizing their total production costs. An additional competitive consideration is offered by Nededog (2015) who argues that shorter seasons serve a specific strategic purpose for networks: they ensure that there is an of- 
fering ready to go when other regular or half-season series end. Thus, there is less handing off of the audience to cable outlets during winter, mid-season, or summer breaks.

In the third category-creative considerations-Hinckley (2013) posits a link between the rise of the "cable model" and season length but with an interesting twist. It's his contention that creators' desire to tell more focused and less "diluted" stories is driving some of the change to shorter seasons. Hinckley also offers an explanation as to the reason why, despite its many merits, the major networks have not gone all-in on the cable-model, i.e. 10 - 13 episode seasons. In short, it comes down to decision rights. It's typically television and studio executives-rather than writers, creators, or actors-who have the final word on decisions about season length. And executives still hold dear the idea that more episodes mean more revenue and the ability to spread fixed costs over a greater number of episodes.

But countering the formal influence of the executives and bolstering that of the creatives is the advent of "Peak TV", the term used to describe the fact that an all-time high of 455 scripted television series aired on American television in 2016 (Ryan, 2016). That number exceeded by 34 the number appearing in 2015 and also represented a $137 \%$ increase over the number appearing a decade prior. In such a competitive environment, one differentiation strategy pursued by both networks and cable producers is to cast bankable stars, often movie stars, and highly-successful show creators. The problem is that such actors and actresses have-by definition-a variety of options and are unwilling to limit them by committing to 20 - 22 episode seasons, ones which involve nine months or more of filming. As for top creators, they have a variety of options as to where to shop their new projects. And more options mean more influence in the length of season decisions which in this case means shorter ones.

While the academic literature is silent on the matter of season length and its determinants, there is related work in the field of cultural economics that bears on the question indirectly. That work focuses on early-stage prediction of the financial performance of feature films (Eliashberg, Hui, \& Zhang, 2014; Hunter, Smith, \& Singh, 2016) and the performance of new television shows (Hunter, Chinta, \& Smith, 2016; Hunter et al., 2016). The common finding in both sets of studies is that screenplays differ in systematic ways that matter for the film's or television series' performance, e.g. box office revenues and number of viewers. In that work focused on the television industry, research has identified three factors that explained variance in viewership levels for new dramatic series: the track record of the series' creators, the originality of the series' premise, and the cognitive complexity of the series' pilot episode. In this paper we use these same three variables-and combinations thereof-to model the number of episodes that new dramatic series received on the four major networks during the nine most recent television seasons. As expected, we find that the same three variables that predict the number of viewers per episode also strongly and positively predict the number of episodes in their first season. In particular, series with origi- 
nal rather than adapted concepts, series whose creators had strong track records of success, and series whose pilot episodes had high cognitive complexity had a significantly higher number of episodes in their first season and were more likely to get a full first season, i.e. 20 or more episodes.

The remainder of this paper is organized as follows. In the next section we briefly review the literature relevant to the intent of this paper and also outline our key hypotheses. In the section that follows we describe our methods and data. In the section after that we describe the results of our analysis while in the concluding section we discuss the most important implications of our findings - both for industry and for the academic literature.

\section{Literature Review \& Hypotheses}

As noted in the introduction, there is a relevant literature in the field of cultural economics that bears directly upon the research question considered herein-the length of a new television series' first season. In general, that research has been concerned with predicting financial performance of feature films (Eliashberg, Hui, \& Zhang, 2014; Hunter, Smith, \& Singh, 2016) and the audience size of new dramatic television series (Hunter, Smith, \& Chinta, 2016; Hunter, Chinta, Smith et al., 2016).

What distinguishes those studies from others is the focus on early-stage prediction of success, where early typically means during the development process. At that juncture, many of the well-known and widely studied predictors of success are not and can not be known. For example, several prior studies have showed that favorable critical reviews and winning (or getting nominated for) Academy Awards are both positive predictors of box office revenues. The problem is that greenlighting decisions-i.e. the decision to finance and produce a film or television series-has to be made well before any of those factors are known. At the stage where this decision must be made, the screenplay (script) and information related to or derived from it often constitute the only objective data that executives have to use in their deliberations (Eliashberg, Hui, \& Zhang, 2014). And this is precisely what this research has shown. Specifically, it has been demonstrated that information derived solely from content and textual analysis of the screenplays, as well as information about their writers, can reliably forecast a film's return on investment (Eliashberg, Hui, \& Zhang, 2007), total box office revenues (Eliashberg, Hui, \& Zhang, 2014), and opening weekend box office (Hunter, Smith, \& Singh, 2016), as well as the audience size of the first season of new, dramatic television series (Hunter, Smith, \& Chinta, 2016; Hunter, Chinta, Smith et al., 2016).

Of especial relevance to our research question are the latter studies by Hunter and colleagues, wherein three content-analytic variables were shown to positively and significantly predict the audience of new television series. These were the originality of the series' premise, the track record of the series' creator(s), and the cognitive complexity of the screenplay of the series' pilot episode. Below we briefly recap the arguments made in support of those three factors. 
Originality was conceptualized such that series which were not derived from previous intellectual property-novels, comic books, musicals, plays, short stories, other television series or franchises, etc.-were considered original. Obviously, this is a content-related factor that can be determined prior to the important green-lighting decision. Based on the slightly negative but significant impact of originality on opening weekend box office, Hunter, Smith \& Chinta (2016) anticipated the same direction and significance for the audience size of original, new television series. Somewhat surprisingly, they found the opposite to be the case: there was a positive and significant relationship between originality and the number of viewers.

The rationale for including creators' Track Record was fairly straight-forward. Drawing on empirical evidence showing that prior success of actors, directors, and screenwriters (Goetzmann, Ravid, \& Sverdlove, 2013), positively predict box office, Hunter, Smith, \& Chinta (2016) anticipated and found that new series from creators with at least one renewed series to their credit would have larger audiences than new series from creators with no successful series to their credit.

Cognitive Complexity has several definitions in the psychology literature, two of which are "the number of independent dimensions of concepts that an individual brings to bear in describing a particular domain of phenomena" (Scott, 1962: p. 405) and "the number of independent constructs a person uses in perceiving and interpreting the environment" (Tinsley, Kass, Moreland \& Harrison, 1983: p. 94). Hunter and colleagues used the size of a concept map constructed from each film's or episode's screenplay as their proxy for cognitive complexity. They found it to be the most positively significant predictor of box office and audience size among all variables in their empirical models. That is to say, the more cognitively complex the screenplay, the greater the opening weekend box office (Hunter, Smith, \& Singh, 2016) and the larger the first season audience (Hunter, Smith, \& Chinta, 2016), especially the initial episodes.

The purpose of the current study is to test whether these same three factors-the story's originality, the creator's track record, and the pilot script's cognitive complexity - will also predict the length of the first season of a new television series, just as they have already been shown to predict the size of their audiences. As such, following the findings of prior research, we propose the following three falsifiable hypotheses:

$\mathrm{H} 1$ : The originality of a story will be positively associated with the length of a new series' first season.

H2: Strong creator track records will be positively associated with the length of a new series' first season.

H3: Cognitive complexity of the pilot episode script will be positively associated with the length of a new series' first season.

\section{Methods and Data}

In order to test our three hypotheses, we first collected data on the total number 
of episodes broadcast in the first season of selected new dramatic series appearing over the last nine seasons (2008-2016). Each of these series appeared in prime-time, in hour-long time slots and premiered on one of the four major networks-ABC, CBS, Fox, and NBC.

Using sources such as Wikipedia, TV Guide, TV.com, and TV Series Finale, we identified over 200 series that debuted between September 1, 2008 and February $28^{\text {th }}, 2017$. Several of these were eliminated for one or more of the following reasons. First we eliminated from consideration those series not produced exclusively in the US, e.g. Welcome to Sweden (2014) which was a joint production of NBC and Swedish Television (SVT). We also eliminated spin-off series whose characters were first introduced in a regular episode of the parent show. These are known as "back-door" pilots and in our sample this included series such as CSI Cyber (2015) and NCIS-LA (2009). We also excluded anthology series, i.e. those where the cast and story line completely changed for the second season, e.g. American Crime (2015). Of the series that remained, we eliminated from consideration those whose screenplays could either not be located, e.g. Chicago Med (2015), or were not publicly available through well-known screenplay outlets such as Script Fly (www.scriptfly.com) or TV Writing (https://sites.google.com/site/tvwriting/). In the end we ended up with 165 series in the dataset that was used to test the three hypotheses.

\subsection{Dependent Variable}

Our measure of the length of the series' first season was taken from two sources-either the series' page on the International Movie Database (IMDb) or its primary Wikipedia page, particularly the "Episodes" sub-section. As shown in Table 1, below, the average number of episodes was 13.7-slightly more than the

Table 1. Descriptive statistics.

\begin{tabular}{lcccc}
\hline Variable & Mean & Std. Dev. & Min & Max \\
\hline Sum & 1.12 & 0.82 & 0 & 3 \\
$\bullet \quad$ Sum $=0$ & 0.24 & 0.43 & 0 & 1 \\
$\bullet \quad$ Sum $=1$ & 0.45 & 0.50 & 0 & 1 \\
$\bullet \quad$ Sum $>1$ & 0.31 & 0.46 & 0 & 1 \\
First Season = Full & 0.22 & 0.41 & 0 & 1 \\
Episodes Aired in Season 1 & 13.7 & 5.4 & 2 & 24 \\
Original Concept & 0.64 & 0.48 & 0 & 1 \\
Track Record & 0.20 & 0.40 & 0 & 1 \\
Complexity & 0.28 & 0.45 & 0 & 1 \\
Year/Season & 2012 & 2.5 & 2008 & 2016 \\
Genre = Crime & 0.30 & 0.46 & 0 & 1 \\
Network = ABC & 0.28 & 0.45 & 0 & 1 \\
Network = CBS & 0.22 & 0.41 & 0 & 1 \\
Network = Fox & 0.20 & 0.40 & 0 & 1 \\
Network = NBC & 0.30 & 0.46 & 0 & 1 \\
\hline
\end{tabular}


"new normal" described above for television series-with a standard deviation of 5.4 episodes, a maximum of 24 episodes (Chicago Fire and Hawaii Five-0) and a minimum of two (Lone Star, Lucky 7, My Generation, and Of Kings and Prophets). The mode of the distribution was 13 with a full 50 of the 165 series (30\%) airing precisely that number of episodes in their first season. The categorical variable named " 1 stFull" was coded " 1 " if the series' first season had 20 or more episodes and coded " 0 " otherwise. As shown in Table 1, only 36 of 165 series (22\%) met this condition.

\subsection{Independent Variables}

\subsubsection{Story Originality}

We determined the originality of each series by consulting its Wikipedia and/or IMDb page wherein we looked for information indicating whether the story was derived from prior source material. Series were considered to be original if and only if they were 1) not an adaptation of a novel, e.g. Astronaut Wives Club (2016) and Resurrection (2013) and 2) not a remake of a foreign television series, e.g. Rake (2014), Game of Silence (2016), Backstrom (2016) or Prime Suspect (2011) and 3) not a spin-off of a current or pre-existing series or franchise, e.g. 24: Legacy (2017), Law \& Order. Los Angeles (2010) and 4) not a revival or re-make or re-imagining of a previously broadcasted show, e.g. Ironside (2010), Knight Rider (2010), Charlie's Angels (2009), The Bionic Woman (2007), and Parenthood, 2010) and 5) not a television adaptation of a feature film, e.g. Rush Hour (2016), Training Day (2016), Minority Report (2016), and Lethal Weapon (2017) or documentary, e.g. Code Black (2016) and 6) not based on a comic series, e.g. The Cape (2011), Constantine (2014), Lucifer (2015), Gotham (2014) or a fairy tale, e.g. Once Upon a Time (2012), Grimm (2011). Additionally, we did not treat as original those series whose characters and basic storylines were previously described in either contemporary literature, e.g. Elementary (2012) which imagines Sherlock Holmes in present-day New York City, in religious scripture, e.g. Of Kings and Prophets, 2017 and Kings (2009), or classical mythology, e.g. American Odyssey (2015); As noted in Table 1, 105 of the 165 series $(64 \%)$ in our sample were coded as original.

\subsubsection{Creator Track Record}

In order to determine the track record of a series' creators we relied exclusively on information contained in the IMDb. As shown in Table 1, there was an average of 1.37 creators per series. The mode of the distribution was one with fully 115 of 165 (70\%) having just one creator, 40 (24\%) having two creators, and the rest three or four. Whenever there was more than one creator listed, the first step was to determine which of the creators had a "written by" credit for the series' pilot episode. We then checked the corresponding "Writer" page for each creator to determine whether they had written the pilot for a series that was subsequently renewed for a full second or later season. While we did not require that this prior, full-season renewal occur on the four networks represented in our sample, in most instances this was the case. We found that just 33 of 165 
(20\%) series had one or more creators with such a track record. Interestingly several of them were associated with more than one series in our sample, e.g. Bruno Heller (Gotham, The Mentalist), Greg Berlanti (No Ordinary Family, Eli Stone), Kevin Williamson (Stalker, The Following), and JJ Abrams (The Undercovers, Fringe), and Alex Kurtzman (Fringe, Sleepy Hollow). Notably, several creators without such track records were also associated with more than one series in or sample, e.g. Kyle Killen (Lone Star, Mind Games, Awake), Chad Hodge (Wayward Pines, PanAm), David Hudgins (Game of Silence, Past Life), David Goyer (Constantine; Flashforward), Jason Richman (Detroit 1-8-7, Lucky 7), Noah Hawley (The Unusuals, My Generation), and Liz Heldens (Mercy, Camp, Deception).

\subsubsection{Cognitive Complexity}

Following Hunter, Smith \& Chinta (2016) we measured cognitive complexity of a series by the number of links contained in the main component of the concept network constructed from the screenplay of the series' pilot episode. In short, the greater the number of links, the greater the cognitive complexity. Across the sample, the average number of links was 54 with a standard deviation of 42 . The max was 225 links in the network of the Fringe (2008) co-written by J. J. Abrams, arguably the industry's most prolific and successful series creator. The smallest network-with only 8 links and thus the least cognitively complex-was that for the musical Smash (2012). Other very small networks-less than 16 links-were those for Chicago Fire (2012), Do No Harm (2013), Extant (2014), Harper's Island (2009), Heart Beat (2016), Mind Games (2014), My Generation (2010), The Red Band Society (2014), and Star (2016). For our statistical analyses we created a categorical variable called COMPLEX that was coded " 1 " if the number of links was greater than 75 , which was the top quartile of the sample, and coded " 0 " otherwise.

\subsection{Control Variables}

To capture unobserved heterogeneity across the four networks-ABC, CBS, Fox, and NBC-we included network dummy (categorical) variables in our regression models. As shown in Table 1, NBC had the largest number of new series in our sample (50 of 165), followed closely by ABC (46), CBS (36), and then Fox (33).

Although all of our series are "dramatic", there are many sub-genres that exist within that sample-adventure, mystery, crime, comedy, action, etc. Because our sample is relatively small and the number of genres potentially very large, as well as somewhat hard to define, we opted to include only one-crime. According to Wikipedia, this genre includes police procedurals "a subgenre of detective fiction that attempts to convincingly depict the activities of a police force as they investigate crimes"... and typically show a "number of police-related topics such as forensics, autopsies, the gathering of evidence, the use of search warrants, and interrogation" (Wikipedia, 2017). This genre is particularly relevant to our study of season length because the stories in police procedurals can be and most fre- 
quently are self-contained. Their common fare is a mystery- or case-of-the-week that most typically does not require storylines or narrative arcs that cover multiple episodes. As such, these series lend themselves to longer seasons, in part due to the absence of the "filler" storylines that are eschewed by creators preferring short seasons. Some 49 of the 165 series in our sample (30\%) fit this broad definition of the "crime" genre. Included among them were $A P B$ (2017) Backstrom (2015), Battle Creek (2015), Elementary (2012), Gang Related (2014), Hawaii Five-0 (2010), Ironside (2013), Law \& Order. Los Angeles (2010), NYC 22 (2012), Southland (2009), Stalker (2014), Unforgettable (2011), and Training Day (2017). Notably, shows in this genre were over-represented among those receiving a full first season, comprising as they did $44 \%$ of that total versus only $26 \%$ of those that did not.

\section{Results}

Table 2 and Table 3 provide the results of two different sets of regression models used to test our hypotheses. In the first are results of five logistic regressions where the dependent variable was the categorical variable indicating whether or not a series aired twenty or more episodes in its first season. Table 3 presents the results of another five Poisson regressions where the dependent variable is the number of episodes that in the series' first season.

\subsection{Modeling the "Full" First Season}

Model 1 in Table 2 shows the results of a baseline model that includes only three control variables for network (ABC, FOX, and $\mathrm{NBC}$ ) as well as the control of genre (CRIME). Notable, the three network variables are all statistically significant at the same level $(p<0.05$, one-tailed) and their coefficients are negative and of roughly the same value $(-1.21<\beta<-0.94)$. This indicates that series on these three networks were equally less likely than the comparison category represented by CBS to have had full first seasons. As such, in future models we replace these three dummy variables with one for CBS. Also notable is that as suspected, CRIME is positive and significant ( $\beta=0.93, p<2.30$, one tailed) indicating that crime series were significantly more likely to have received a full first season. As we see from Model 2, when CBS replaces the three other network dummies, the model is more significant as a whole ( $p<0.01$, one-tailed) while both the log likelihood and the pseudo- $\mathrm{R}^{2}$ values are essentially unchanged. In Model 3 we include SUM as our first independent variable which was the sum of the three independent variables-ORIGINALITY, TRACKRECORD, and COMPLEXITY. If a series was not coded as original, its creators' track record nonexistent, and its concept network not complex, then SUM was equal to zero. If all three conditions were met, then SUM was equal to three.

In the intermediate cases SUM was equal to one or two. The coefficient on SUM clearly indicates that the more of the three conditions that were met, the greater the likelihood of a series having received a full first season. This result essentially confirms that broadly speaking, the three criteria previously identified 
Table 2. Logistic regression where the dependent variable is categorical and coded " 1 " if new dramatic television series had a "Full" first season, i.e. 20 or more episodes, and Coded "0" otherwise.

\begin{tabular}{|c|c|c|c|c|c|}
\hline & Model 1 & Model 2 & Model 3 & Model 4 & Model 5 \\
\hline Sum & & & $\begin{array}{c}0.92^{* * *} \\
(3.48)\end{array}$ & & \\
\hline Sum $=1$ & & & & $\begin{array}{l}1.19^{*} \\
(1.78)\end{array}$ & \\
\hline Sum $>1$ & & & & $\begin{array}{l}2.00^{* *} \\
(2.92)\end{array}$ & \\
\hline Originality & & & & & $\begin{array}{l}\mathbf{0 . 8 5 ^ { * }} \\
(1.79)\end{array}$ \\
\hline Track Record & & & & & $\begin{array}{l}0.71^{\#} \\
(1.51)\end{array}$ \\
\hline Complexity & & & & & $\begin{array}{c}1.16^{* * *} \\
(2.76)\end{array}$ \\
\hline Crime & $\begin{array}{l}0.82^{*} \\
(2.04)\end{array}$ & $\begin{array}{l}0.80^{*} \\
(2.00)\end{array}$ & $\begin{array}{l}0.93^{* *} \\
(2.19)\end{array}$ & $\begin{array}{l}0.92^{*} \\
(2.21)\end{array}$ & $\begin{array}{l}0.89^{*} \\
(2.05)\end{array}$ \\
\hline $\mathrm{ABC}$ & $\begin{array}{l}-1.03^{*} \\
(-1.96)\end{array}$ & & & & \\
\hline FOX & $\begin{array}{l}-1.31^{*} \\
(-2.18)\end{array}$ & & & & \\
\hline NBC & $\begin{array}{l}-1.00^{*} \\
(-1.98)\end{array}$ & & & & \\
\hline CBS & & $\begin{array}{l}1.09 * * \\
(2.60)\end{array}$ & $\begin{array}{l}0.92^{*} \\
(2.08)\end{array}$ & $\begin{array}{l}0.85^{*} \\
(1.95)\end{array}$ & $\begin{array}{l}0.87^{*} \\
(1.95)\end{array}$ \\
\hline Model df & 4 & 1 & 3 & 4 & 5 \\
\hline Model $\chi^{2}$ & $11.4^{*}$ & $11.1^{\star *}$ & $24.5^{\star * * *}$ & $22.7^{\star * *}$ & $25.0^{* * * *}$ \\
\hline Log Likelihood & -80.9 & -81.0 & -74.3 & -77.4 & -74.0 \\
\hline Pseudo- $\mathrm{R}^{2}$ & $6.6 \%$ & $6.4 \%$ & $14.1 \%$ & $12.8 \%$ & $14.5 \%$ \\
\hline
\end{tabular}

by Hunter and colleagues also explain variation in season length in the current sample. In Model 4, SUM is replaced with two other categorical variablesSUM $=1$ which is coded " 1 " when the SUM was equal to " 1 " and coded "0" otherwise-and SUM $>1$ which is similarly coded to represent when SUM was equal to two or three. The coefficients on these variables indicate that the likelihood of a full first season was somewhat higher when one of the three conditions was met (SUM $=1: \beta=1.19, p<0.05$, one-tailed) and even higher when two or three of the conditions were met (SUM $>1: \beta=2.00, p<0.01$, one-tailed). In Model 5 we include three categorical variables ORIGINALITY, TRACKRECORD, and COMPLEXITY. What we see here is that while COMPEXITY is by far the most statistically significant of the three factors $(\beta=1.19, p<0.01$, one-tailed), the other two are statistically significant, but only marginally so (ORIGINAL, $\beta=$ $0.66, p<0.10$; TRACKRECORD, $\beta=0.69, p<0.10$, both one-tailed). Taken to- 
gether, these results suggest quite strong support for our third hypothesis-that cognitive complexity is positively associated with season length-but only modest support for our first and second hypotheses-that story originality (H1) and creator track record (H2) were positively associated with season length. Also noteworthy is that in Model 5, log likelihood and the pseudo- $\mathrm{R}^{2}$ values are the greatest, thereby indicating that this model has the most explanatory model of the five.

\subsection{Modeling the Number of Episodes in the First Season}

The Poisson regression models 1 - 5 in Table 3 are three structured exactly in parallel to the logistic regression models in Table 2. The results are almost same, as well. In Model 1 we again see that CRIME, the dummy variable representing the police procedural genre, is positive and significant at about the same level ( $\beta=0.13, p<0.01$, one-tailed) as in the logistic regression Model 1. So too are

Table 3. Poisson regression where dependent variable is count of the number of episodes of a new dramatic television series that aired in its first season.

\begin{tabular}{|c|c|c|c|c|c|}
\hline & Model 1 & Model 2 & Model 3 & Model 4 & Model 5 \\
\hline Sum & & & 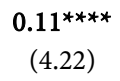 & & \\
\hline Sum $=1$ & & & & $\begin{array}{l}0.16^{*} \\
(2.71)\end{array}$ & \\
\hline Sum $>1$ & & & & $\begin{array}{l}0.27^{* *} \\
(4.45)\end{array}$ & \\
\hline Originality & & & & & $\begin{array}{l}0.10^{*} \\
(2.28)\end{array}$ \\
\hline Track Record & & & & & $\begin{array}{l}\mathbf{0 . 1 1 ^ { * }} \\
(2.11)\end{array}$ \\
\hline Complexity & & & & & $\begin{array}{l}0.12^{* *} \\
(2.49)\end{array}$ \\
\hline Crime & 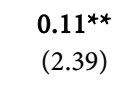 & $\begin{array}{l}0.11^{\star *} \\
(2.44)\end{array}$ & $\begin{array}{c}0.12^{* *} \\
(2.56)\end{array}$ & $\begin{array}{c}0.11^{\star *} \\
(2.43)\end{array}$ & $\begin{array}{l}0.11^{* *} \\
(2.49)\end{array}$ \\
\hline $\mathrm{ABC}$ & $\begin{array}{c}-0.33^{* * * *} \\
(-5.60)\end{array}$ & & & & \\
\hline FOX & $\begin{array}{c}-0.28^{* * * *} \\
(-4.44)\end{array}$ & & & & \\
\hline NBC & $\begin{array}{c}-0.25^{* * * *} \\
(-4.49)\end{array}$ & & & & \\
\hline CBS & & $\begin{array}{c}0.29 * * * * \\
(6.04)\end{array}$ & $\begin{array}{c}0.25^{\star * * *} \\
(5.26)\end{array}$ & $\begin{array}{c}0.25^{* * * *} \\
(5.12)\end{array}$ & $\begin{array}{c}0.25^{* * * *} \\
(5.17)\end{array}$ \\
\hline Model df & 4 & 2 & 3 & 4 & 5 \\
\hline Model $\chi^{2}$ & $44.9^{* * * *}$ & $43.1^{\star * * *}$ & $60.8^{\star * * *}$ & $63.4^{* * * *}$ & $60.8^{* * * *}$ \\
\hline Log Likelihood & -522.6 & -523.5 & -514.6 & -513.3 & -514.6 \\
\hline Pseudo- $\mathrm{R}^{2}$ & $4.1 \%$ & $4.0 \%$ & $5.6 \%$ & $5.8 \%$ & $5.6 \%$ \\
\hline
\end{tabular}

Legend: ${ }^{*}=p<0.05 ;^{* *}=p<0.01 ;{ }^{* *}=p<0.001 ;^{* * *}=p<0.0001$, all one-tailed; $\mathrm{n}=165$ observations. 
the three network dummies. As such, it again makes sense in Model 2 to replace the three network dummies with one for CBS which is much more highly significant here than above ( $\beta=0.26, p<0.0001$, one-tailed). And again, in Model 3, the continuous variable SUM is positive and significant $(\beta=0.12, p<0.0001)$ while in Model 4, SUM1 is more significant than the baseline condition where, i.e. SUM $=0(\beta=0.12, p<0.01$, one-tailed $)$ and SUM23 is even more so $(\beta=$ $0.23, p<0.0001$, one-tailed). Also, as in Model 5 above, COMPLEXITY is the most significant predictor $(\beta=0.12, p<0.01)$, followed by TRACKRECORD $(\beta=$ $0.12, p<0.05$, one-tailed) and ORIGINALITY ( $\beta=0.10, p<0.05$, one-tailed). Finally, Model 5 again has the greatest explanatory power as evidenced by it having the largest $\log$ likelihood (-543.6) and Pseudo- $\mathrm{R}^{2}$ (5.4\%), albeit here essentially tied with Model 3 . Taken together, these results offer very strong support for all three of our hypotheses, i.e. that story originality (H1), creator track record (H2), and cognitive complexity (H3) are positively associated with season length.

Table 4 below complements the results of the two sets of regression models, providing information not obvious from the above interpretations. One interesting fact is that there were 39 series in our sample that met the baseline or null condition, i.e. $\mathrm{SUM}=0$. Of these forty, only one received a full first season-LaW \& Order. Los Angeles (2010), an extension of one of television's most popular franchises and one belonging to our CRIME genre. Save this one exception, series that were unoriginal, whose creators had no track record (as we defined it), and whose teleplays were not complex never received a full first season. In marked contrast, the 75 series that met at least one of the three conditions had a $19 \%$ chance of receiving a full first season, almost 8 times as many. As for those 51 series that had two or three factors present: $36 \%$ of them had a full first season, over 14 times as many as those with none of the three. We also see from Table 4 that series having none of the three average 11 episodes while those with one factor had almost 2.4 more episodes, a $21 \%$ improvement. Series with two or three factors average 15.6 episodes-a $38 \%$ improvement.

Taken together the results of the two regressions strongly support our three hypotheses, namely, that story originality $(\mathrm{H} 1)$, creator track record (H2), and cognitive complexity (H3) are positively associated with season length. Implications of these findings for the body of relevant literature are discussed in the next section.

\section{Discussion}

As noted in the literature review, prior research-principally that of Hunter and

Table 4. First season and number of episodes in first season by value of independent variable "Sum".

\begin{tabular}{ccc}
\hline Group & Full First Season? & Episodes in First Season \\
\hline Sum $=0$ & 1 of $39(2.5 \%)$ & 11.3 \\
Sum $=1$ & 15 of $75(19 \%)$ & 13.7 \\
Sum $>1$ & 20 of $51(36 \%)$ & 15.6 \\
\hline
\end{tabular}


colleagues-has already demonstrated that the three factors studied here were positively and significantly associated with the audience size of new dramatic television series. Notably, all of these series, plus an additional four seasons worth, are included in our sample. To the prior literature we can now add the present finding concerning season length. Strictly speaking, season lengthwhether measured categorically or as the number of episodes-is not a measure of performance. But we might think of it as "pre-performance." That's because executives at the major networks prefer longer seasons because they offer the opportunity to maximize gross revenue and to spread fixed costs of their development budgets over a greater number of episodes. To those incentives, our results can provide something additional. Consider Table 5, below which adds to Table 4 information about how the series in the sample performed. The series are placed into three categories-those where the independent variable SUM was equal to zero, one, or more than one. In the fourth column we have an indication of what percentage got renewed for a second season of any length. In the fifth column we see what number received a full second season. The sixth and last column tells how many of those receiving a full season "graduated" to that status from half-season runs. The bottom row compares the zero-factor (Sum = 0 ) and multi-factor (Sum $>1$ ) conditions.

As we noted previously, the probability of getting a full first season was 15 times greater for those series where any two of the three factors were present compared to those where none were present ( $39 \%$ vs. $2.6 \%$ ). Interestingly, we can see that the relative percentages concerning full second seasons are even greater. Specifically, the probability of a series getting a full second season when two or more factors were present was $33 \%$ while the rate for series with no factors present was $0 \%$. Technically the difference is infinite but for practical purposes we indicate the quantity as greater than 50 -fold. Also notable is the fact that the chances of getting renewed for a season of any length are double for the multi-factor group (43\%) compared to the zero-factor group (22\%). Finally, note

Table 5. Comparison of season duration and renewal statistics by value of independent variable "Sum".

\begin{tabular}{|c|c|c|c|c|c|}
\hline Group & $\begin{array}{c}\text { Full First } \\
\text { Season }\end{array}$ & $\begin{array}{l}\text { Episodes in } \\
\text { First Season }\end{array}$ & $\begin{array}{c}\text { Renewed } \\
\text { for a } \\
\text { Second } \\
\text { Season }\end{array}$ & $\begin{array}{c}\text { Full Second } \\
\text { Season }\end{array}$ & $\begin{array}{l}\text { "Graduates" to } \\
\text { Full Second } \\
\text { Season }\end{array}$ \\
\hline Sum $=0$ & $\begin{array}{l}1 \text { of } 39 \\
(2.6 \%)^{*}\end{array}$ & 11.3 & $\begin{array}{c}8 \text { of } 36 \\
(22 \%)\end{array}$ & $\begin{array}{c}0 \text { in } 36 \\
(0 \%)\end{array}$ & 0 \\
\hline Sum $=1$ & $\begin{array}{c}15 \text { of } 75 \\
(20 \%)\end{array}$ & 13.7 & $\begin{array}{c}23 \text { of } 72 \\
(32 \%)\end{array}$ & $\begin{array}{c}12 \text { of } 71 \\
(17 \%)\end{array}$ & $3^{\#}$ \\
\hline Sum $>1$ & $\begin{array}{c}20 \text { of } 51 \\
(39 \%)\end{array}$ & 15.6 & $\begin{array}{c}19 \text { of } 44 \\
(43 \%)\end{array}$ & $\begin{array}{c}14 \text { of } 43 \\
(33 \%)\end{array}$ & $2^{@}$ \\
\hline $\begin{array}{c}\text { Sum }>1 \text { vs. } \\
\text { Sum }=0\end{array}$ & $15 x$ & $1.4 \mathrm{x}$ & $2 \mathrm{x}$ & $>50 \mathrm{x}$ & \\
\hline
\end{tabular}

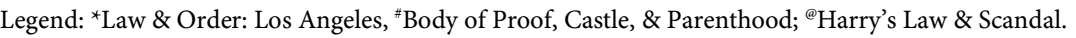


that while in the zero-factor group, not one of these series "graduated" from short first season full second season, in the single- and multi-factor series, there were five such graduates. In the former case these were Body of Proof (2011), Castle (2009), and Parenthood (2010) while in the latter, Harry's Law (2011) and Scandal (2012). All the rest that had full seasons were ones that began as such. This suggests, if nothing else, that many series stay as they are initially as it pertains to season length. And that fact emphasizes the usefulness of our findings for the executives who make the decisions about this matter. Were we to summarize what guidance they should take from our results it would be this: given the choice between greenlighting two or more series, opt for those with the greater number of the three factors present. All else equal, those with 2 - 3 factors present have historically been over 15 times more likely to be worthy of a full first season, twice as likely to be renewed, and over 50 times as likely to get a full second season. To that we might add, when determining the fate of existing series-perhaps when deciding whether to renew series or to graduate it to full-season status-give greater consideration to those with more factors present.

There is also guidance here for show creators. Hunter's (2014) initial studies on the network text analysis of screenplays suggested a very strong link between network size (which is a proxy for cognitive complexity) and the use of context-specific jargon or lexicon that signifies knowledge of the "subject, setting, role, events, and values" that establish an audience's genre expectations (McKee, 2010: p. 80). Here's what that work and this one specifically suggest for creators aiming to write what could become series that run for multiple full seasons: deeply research your topic so that your pilot reflects deep knowledge of the domain, be it sports, aviation, police work, medicine, law, espionage, space travel, etc. The poor performance-both in terms of audience size and season lengthof low complexity screenplays suggests that audiences have a subjective sense of complexity. That said, if the creator wants to develop a series that will be less about interesting objects and actions, and is more interpersonal and in-depth as it pertains to character, then the research expectation takes a back seat to knowing what makes that particular or those particular characters "tick." That knowledge won't necessarily be reflected in the kind of conceptual vocabulary that is high in cognitive complexity as measured here.

\section{References}

Adalian, J. (2015, June 12). 10 Episodes Is the New 13 (Was the New 22). http://www.vulture.com/2015/06/10-episodes-is-the-new-13-was-the-new-22.html

Brew, S. (2014, March 25). The Problem with 22 Episode Seasons. http://www.denofgeek.com/tv/us-tv/29834/the-problem-with-22-episode-seasons

Crupi, A. (2011, July 27). More Broadcast Series Get 13-Episode Short Orders. More Broadcast Series Get 13-Episode Short Orders. http://www.adweek.com/tv-video/more-broadcast-series-get-13-episode-short-orders133686/

Eliashberg, J., Hui, S. K., \& Zhang, Z. J. (2007). From Story Line to Box Office: A New Approach for Green-Lighting Movie Scripts. Management Science, 53, 881-893. 
Eliashberg, J., Hui, S. K., \& Zhang, Z. J. (2014). Assessing Box Office Performance Using Movie Scripts: A Kernel-Based Approach. IEEE Transactions on Knowledge and Data Engineering, 26, 2639-2648. https://doi.org/10.1109/TKDE.2014.2306681

Goetzmann, W. N., Ravid, S. A., \& Sverdlove, R. (2013). The Pricing of Soft and Hard Information: Economic Lessons from Screenplay Sales. Journal of Cultural Economics, 37, 271-307. https://doi.org/10.1007/s10824-012-9183-5

Hinckley, D. (2013, July 7). TV Is Moving towards Shorter Seasons. New York Daily News.

http://www.nydailynews.com/entertainment/tv-movies/tv-moving-shorter-seasons-arti cle-1.1387581

Humphrey, H. (1968, January 23). Viewers Getting Less and Less. Los Angeles Times. http://www.macleans.ca/authors/jaime-weinman/how-u-s-tv-wound-up-with-fewer-ep isodes/

Hunter, S. (2014). A Novel Method of Network Text Analysis. Open Journal of Modern Linguistics, 4, 350-366. https://doi.org/10.4236/ojml.2014.42028

Hunter, S. D., Smith, S., \& Chinta, R. (2016). Predicting New TV Series Ratings from their Pilot Episode Scripts. International Journal of English Linguistics, 6, 1-11. https://doi.org/10.5539/ijel.v6n5p1

Hunter, S., Chinta, R., Smith, S., Shamim, A., \& Bawazir, A. (2016). Moneyball for TV: A Model for Forecasting the Audience of New Dramatic Television Series. Studies in Media and Communication, 4, 13-22. https://doi.org/10.11114/smc.v4i2.1611

Hunter, S., Smith, S., \& Singh, S. (2016). Predicting Box Office from the Screenplay: A Text Analytical Approach. Journal of Screenwriting, 7, 135-154.

https://doi.org/10.1386/josc.7.2.135_1

Lynch, J. (2015, April 13). Power of 10: Why Networks Are Ordering Shorter Seasons for Their Hit Shows.

https://qz.com/382478/power-of-10-why-networks-are-ordering-shorter-seasons-for-t heir-hit-shows/

McKee, R. (2010). Substance, Structure, Style, and the Principles of Screenwriting. New York: Harper Collins.

Nededog, J. (2015, June 18). 5 Reasons Why TV Networks Are Ordering Shorter Seasons. http://www.businessinsider.com/why-tv-networks-are-ordering-shorter-seasons-2015$\underline{6}$

Ryan, M. (2016, December 21). TV Peaks Again in 2016: Could It Hit 500 Shows in 2017? Variety.

http://variety.com/2016/tv/news/peak-tv-2016-scripted-tv-programs-1201944237/

Scott, W. A. (1962). Cognitive Complexity and Cognitive Flexibility. Sociometry, 25, 405-414. https://doi.org/10.2307/2785779

Tinsley, H. E., Kass, R. A., Moreland, J. R., \& Harren, V. A. (1983). A Longitudinal Study of Female College Students' Occupational Decision Making. The Career Development Quarterly, 32, 89-102. https://doi.org/10.1002/j.2164-585x.1983.tb01563.x

Weinman, J. (2010, March 18). How US Television Wound Up with Fewer Episodes. Maclean's.

http://www.macleans.ca/authors/jaime-weinman/how-u-s-tv-wound-up-with-fewer-ep isodes/ 
Submit or recommend next manuscript to SCIRP and we will provide best service for you:

Accepting pre-submission inquiries through Email, Facebook, LinkedIn, Twitter, etc. A wide selection of journals (inclusive of 9 subjects, more than 200 journals)

Providing 24-hour high-quality service

User-friendly online submission system

Fair and swift peer-review system

Efficient typesetting and proofreading procedure

Display of the result of downloads and visits, as well as the number of cited articles Maximum dissemination of your research work

Submit your manuscript at: http://papersubmission.scirp.org/

Or contact ajc@scirp.org 